\title{
The effectiveness of occupational therapy intervention on moderate Intellectually challenged (Mentally Retardation)
}

\author{
M. Ramakrishnan \\ MOT (mental health), Occupational therapist, department of psychiatry, JIPMER Hospital, Pondy-4, India
}

\begin{abstract}
This descriptive case study illustrates the experience of a 24 years old male with a moderate Intellectually challenged(Mentally Retarded) with the problem of speech and language, lack of motivation and impaired functional skills are rehabilitated by the therapist using occupation-based interventions on OPD basis. The participant engaged in occupation-based interventions daily for 16 weeks (four months) in the occupational therapy department. The plan for the therapy is to motivate the person to engage in weaving and improve his functional skills and make him to independent in all areas. After the intervention the improvement seen in the self-care, work and leisure.
\end{abstract}

\section{Introduction}

Intellectually challenged (Mental Retardation) is a developmental disability that first appears in children under the age of 18. It is characterized by significant sub intellectual functioning, existing concurrently with related limitation in two or more of the following applicable adaptive skill areas: communication, self-care, home living, social skill, community use, self-direction, health and safety, functional academics, leisure and work. Intellectually challenged (Mental Retardation) manifests before age eight.

Outline of occupational therapy approaches ${ }^{(8,9,10)}$ used in mental retardation are:

- Developmental approach

- Sensory motor approach

- Perceptual-motor approach

- Sensory stimulation approach

- Behavior modification technique

Table 1 Classification of Intellectually challenged (Mental Retardation)

\begin{tabular}{l|l|l|l}
\hline Severity & $\begin{array}{l}\text { Intelligence } \\
\text { Quotient }\end{array}$ & Education & Adult Academic Abilities \\
\hline Mild & 70 to $55-50$ & Educable & Elementary grade skills \\
$\begin{array}{l}\text { Moderate } \\
\text { Severe/Profound }\end{array}$ & $\begin{array}{l}55-50 \text { to } 50-35 \\
\text { Basic tasks }\end{array}$ & Trainable & Early Elementary grade skills \\
Emphasis on self-care skills
\end{tabular}

behavior modification technique is used to enhance learning by identifying target behavior, identifying rein-forcers, factors affecting rein-forcers(depression, satiation, immediacy of rein forcers), teaching in small graduated steps, methods of teaching(forward chaining and backward chaining), shaping, modeling, total task presentation, splinter skills, one to one teacher guidance(prompts), maintenance of behavior(schedules of reinforcement), generalization and discrimination ${ }^{(1,2,3,5,6,7)}$.

\section{Case description}

A case of moderate Intellectually challenged (mentally retardation), age of 24 years old illiterate background and the symptoms of not cooperative to adults at home, with speech and language problems and also not going for work settings. He is stated that impaired functional skills and motivation less. He is always rooming outside the home. He is interested in playing cricket with his peer groups on the playground and not interested in watching the movies and listening songs and he is interested only in listening music ragas. He is capable of doing self-care independently. And also is the part of engaging in simple tasks like making paper envelope and the woolen thread mat weaving. Currently he is living with his parents. Apart from this then plan for go to Government vocational training center for his future life. On medical history from childhood he is having fits and has being treated for his illness in various places. He is not showing any visible symptom of fits and being continued in taking medication. Finally he brought to the psychiatry department, JIPMER Hospital for further rehabilitation. Here he advised to continue occupational therapy for vocational counseling and vocational rehabilitation. 
He learnt the task and work in the department with minimal supervision. He is able to complete the task fully and also improved concentration well. The occupational therapy plan is to educate him in maintain the self-care and the teaching the simple task such as paper envelope which has two components and the task of woolen weaving as a telephone mat. Therapy sessions are 3 Session/Day, 24 Session/Week for 16 Weeks. And also to teach the basic life skills. And motivate him go to vocational center for learning any suitable vocation.

\section{Discussion}

The subject was assessed IQ level by the clinical psychologist. Moderately intellectually challenged children were selected as they are considered to be trainable and can learn to care for their daily needs (Fred Biasini, Lisa Grupe, Lisa Hoffman, Norman Bray) ${ }^{4}$. He was trainable and can learn to care for his daily needs and also to able to learn a simple task skills such as woolen mate weaving with the required readymade materials of wooden and the thread. Then he was learnt the task of paper envelope which are taught by the therapist in the occupational therapy within a week. Here the various occupational therapy approaches are used for learning the task and the improve his functional skills. He succeeded the entire task with slowly before that he was not exposed these types of skills so for. And he also was given the home task of coloring the picture which he completed the drawing self. Here it was used forward chain technique. Each time he was rewarded as verbal praise by the therapist when he succeeded the given the task in the department. He was able to sit and do the task for more than three hours in the morning session.

Then he took rest at home in the afternoon. Here it was found that adequate attention, absence of wandering tendency, self-injurious behavior. For memory retention ask him to do the same task of woolen regularly in the department. Sometimes he was not able to come to the department due to family issues like caregivers not coming along with him and bodily pain. Speech and language problems are cared by the other allied professionals. He completed the therapy for three months after that he went to Government vocational settings for his future career. He continued the vocation of hand loom weaving under supervision of vocational counselor in the Government Sector.

\section{Conclusion}

The findings of the study are consistent with the assumption. This suggests that intellectually challenged (moderate Mentally Retarded) children are capable of learning through efficient occupational therapy programme to a far greater extent.

\section{References}

[1]. Bender, Michael, Velletulti, J.Peter (1976) Teaching the moderately and severely handicapped: Curriculum Objective Strategies and Activities. University Park Press, Vol.1.

[2]. Brower, M Lester: The Occupational Therapist's Role with Mentally Retarded Children (1961) AJOT. Vol.2, (61-62).

[3]. Burke, Bearldean B: The changing concepts \& function of Occupational Therapy for the Mentally Retarded children (1967) AJOT. Vol.2, (57-60).

[4]. Biasini Fred, Grupe Lisa, Huffman Lisa, Bray W.Norman, Mental Retardation: A Symptom and syndrome.

[5]. Hickson.Linda, Blackman S. Leonard, Elizabeth (1995). Mental Retardation: Foundation of Education and Programming, Publication Allyn and Bacon.

[6]. Hilgard, Ernest R \& Atkinson, Richard C (1975): An Introduction to Psychology, Published by Mohan Primiani for Oxford \&I.B.H.Pub. Co.Pvt.Ltd.66 Jan path, NDL.

[7]. Hughes, C, Hugo, K, \& Blatt, J. (1996). Self-instructional intervention for teaching generalized problem solving with in a functional task sequence American Journal on mentally retardation Vol.100. (565-579)

[8]. Pratt, PatNuse\&Allen, Anne Stevens $(1989) 2^{\text {nd }}$ ed.: Occupational therapy for children, the C.V.Mosby company (St.Louis, Baltimore).

[9]. Wiilard\&Spackman (1993) eight edition Willard\&Spackman’s Occupational Therapy, J.B.LippinCott company Philadelphia.

[10]. Trombly, CatherineA.Occupational Therapy for the Physical Dysfunction4th edition, Williams, Wikins, BaltimorePhiladelphia. 